at risk of protracted low-dose exposure to uranium we investigated the relationship between external radiation dose and cardiovascular mortality.

Methods Individual annual and cumulative whole-body equivalent doses were reconstructed for 2897 workers $(79892$ person-years) employed for 6 months at least at the Pierrelatteplant (1960-2006) and monitored for external radiation exposure. Excess Relative Risks per milliSievert (ERR/mSv) were estimated using Poisson regression model stratified on sex, $5 y$ age and calendar period; doses were $5 y$-lagged. Associated 95\% CI were calculated using Maximum Likelihood method.

Results At 31/12/2006, 111 deaths from cardiovascular causes were observed: 48 from ischemic and 31 from cerebrovascular diseases. The mean external dose was $17.5 \pm 28.3 \mathrm{mSv}$ cumulated throughout $19 y$-monitoring duration in average. 542 workers received doses $(3.9 \pm 10.9 \mathrm{mSv}$ in average) previous to their Pierrelatte-plant employment. No dose-response relationship was observed: ERR/mSv was $0.13(-0.09 ; 0.81)$ for all cardiovascular diseases, $0.06(? ; 1.27)$ for ischemic diseases, and $-0.07(-0.30 ; 0.91)$ for cerebrovascular diseases.

Conclusions External radiation exposure appears unrelated to cardiovascular mortality among the Pierrelatte worker cohort. However, since uranium is mostly harmful after intake and only a few uranium isotopes emit penetrating radiation, external dose addresses only partially the health risk after uranium exposure. This risk should be assessed using internal radiation dose or its more accurate proxy. External doses received previously to Pierrelatte-plant employment are very small and are unlikely confounding this risk estimation.

\title{
Poster-discussion: Radiation
}

RELATIONSHIP BETWEEN OCCUPATIONAL EXPOSURE TO URANIUM AND CARDIOVASCULAR MORTALITY: EFFECTS OF EXTERNAL RADIATION

Jerome-Philippe Garsi, ${ }^{1}$ Irina Guseva Canu, ${ }^{1}$ Sylvaine Caer-Lorho, ${ }^{1}$ Alain Acker, ${ }^{2}$ Christine Niogret, ${ }^{2}$ Dominique Laurier ${ }^{1}{ }^{1} / R S N$, Fontenay aux Roses, France; ${ }^{2}$ AREVA NC, Paris, France

10.1136/oemed-2011-100382.282

Objectives Uranium emits $\alpha$-radiation, but may also emit xand $\gamma$-rays. This penetrating radiation is monitored individually by film-badges. In the cohort of French nuclear workers 